\title{
NOV-002, A Glutathione Disulfide Mimetic, Suppresses Tumor Cell Invasion and Metastasis
}

\author{
Kiranmai Gumireddy ${ }^{1 \#}$, Anping Li ${ }^{1 \#}$, Lili Cao ${ }^{1,2}$, Jinchun Yan ${ }^{3}$, Lin Liü ${ }^{1,4}$, Xiaowei Xü ${ }^{5}$ Christopher Pazoles ${ }^{6}$ and Qihong Huang ${ }^{1 *}$ \\ ${ }^{1}$ The Wistar Institute, 3601 Spruce Street, Philadelphia, PA 19104, USA \\ ${ }^{2}$ Central labortary, Shandong Provincial Qianfoshan Hospital, Jinan, Shandong 250014, P. R. China \\ ${ }^{3}$ University of Washington Medical Center, 1959 N.E. Pacific Street, Seattle, WA 98195, USA \\ ${ }^{4}$ Department of Oncology, Shandong Cancer Hospital and Institute, Jinan, Shandong 250117, P. R. China \\ ${ }^{5}$ Department of Pathology and Laboratory Medicine, Hospital of the University of Pennsylvania, Philadelphia, PA 19104, USA \\ ${ }^{6}$ Novelos Therapeutics Inc. One Gateway Center, Newton, MA 02458, USA \\ \#These authors contributed equally to this study
}

\begin{abstract}
Metastasis is the major cause of death in cancer. Most therapies currently in the clinic aim to eradicate primary tumor, but do not have ideal effects on metastasis. The lack of effective therapy in metastasis prevention and treatment results in high mortality rate in cancer patients with advanced diseases. Here we report the oxidized glutathione small molecule compound NOV-002 reduces cancer cell invasion in vitro and metastasis in an animal model in combination with chemotherapy drug gemcitabine. NOV-002 regulates cell signaling pathways by suppressing ErbB2 and PI3K phosphorylation and subsequent inhibition of Akt and RhoA activation. Our results suggest that NOV-002 affects cell signaling pathways that are critical for invasion and metastasis and can potentially be effective in metastasis treatment in combination of other chemotherapies.
\end{abstract}

\section{Introduction}

Metastasis is the formation of tumors at distant sites following the spread of cancer from a primary site [1-3]. When cancer is detected before it has spread, it can often be treated successfully with surgery, radiation and chemotherapy. However when it is detected after it has metastasized, treatments are much less successful [2]. Furthermore, due to the lack of diagnostic tools, many patients in whom there is no evidence of metastasis at the time of their initial diagnosis, develop metastases later [4]. Metastasis, rather than the primary tumor, is thus responsible for the majority of cancer deaths, and has consequently become the most feared aspect of cancer [5].

Metastasis occurs via a multi-step process requiring the coordinated action of a number of genes [6-8]. The completion of this complex journey requires coordination among the genes responsible for each step of the metastatic process. It has been shown that multiple cell signaling pathways either promote or suppress metastasis [6-8]. ErbB2 signaling network is one the pathway responsible for metastasis. ErbB2 is a member of subclass I of the receptor tyrosine kinase superfamily [9-12]. ErbB2 plays important roles in human cancer. The expression or activation of ERBB2 is altered in many epithelial tumors such as breast, ovarian, gastric and non-small-cell lung cancers [13-16]. ErbB2 is also critical in tumor metastasis [17-21]. ErbB2 activation leads to the stimulation of many cell signaling pathways such as phophatidylinositol 3-kinase (PI3K)-AKT pathways, STAT pathways, Mitogen-Activated Protein Kinase (MAPK) pathways and SRC tyrosine kinase pathways [9-12]. The signaling pathway of ErbB2 and its downstream signaling molecules have been heavily investigated; however, the regulation of ErbB2 by redox homeostasis and its impacts on cellular processes have not been extensively studied.

NOV-002, composed of the disodium salt of glutathione disulfide in a 1,000:1 ratio with cisplatin, is a mimetic of oxidized glutathione (GSSG) that regulates oxidative signaling. It has been shown that NOV002 modulates cellular redox balance in human HL-60 cells [22,23]. It reduces cell surface protein thiols which has been shown to serve as sensors for redox conditions and regulate cell signaling pathways in a variety of cellular processes [22,23]. NOV-002 exerts pleiotropic effects on cell signaling pathways. It activates the JNK pathway which is responsible for cell proliferation [22,23]. It has also been shown that GSSG can activate MAPK signaling pathway that leads to cell death $[24,25]$. The effects of GSSG in cell signaling regulation are cell type specific.

Although redox regulation by NOV-002 results in pleiotropic effects on cell functions, its impacts on metastasis have not been studied. Here we showed that NOV-002 regulates ErbB2-PI3K signaling pathway and suppresses cell invasion in vitro and metastasis in vivo in combination with chemotherapy drug gemcitabine.

\section{Materials and Methods}

\section{Antibodies and reagents}

Anti-human Akt, phospho-Akt-(Thr-308), were purchased from Cell Signaling Technology (Beverly, MA); ErbB2, phosphorylated Tyrosine, clone 4G10, PI3 kinase p85, and RhoA activation assay kit were purchased from Upstate Biotechnology (Lake Placid, NY).

\section{Cell culture}

Human cancer cell lines HCT15, MDA-MB-436, A549, SKOV3 and mouse breast cancer cell line 4T1 were cultured in DMEM, HCT116 cells in McCoy 5A medium, Colo205 in RPMI medium, with 10\% fetal bovine serum (FBS). All cells were grown at $37^{\circ} \mathrm{C}$ with $5 \% \mathrm{CO} 2$.

*Corresponding author: Qihong Huang, The Wistar Institute, 3601 Spruce Street, Philadelphia, PA 19104, USA, E-mail: mailto:qhuang@wistar.org

Received March 04, 2013; Accepted April 26, 2013; Published April 30, 2013

Citation: Gumireddy K, Li A, Cao L, Yan J, Liu L, et al. (2013) NOV-002, A Glutathione Disulfide Mimetic, Suppresses Tumor Cell Invasion and Metastasis. J Carcinogene Mutagene S7:002. doi:10.4172/2157-2518.S7-002

Copyright: (c) 2013 Gumireddy K, et al. This is an open-access article distributed under the terms of the Creative Commons Attribution License, which permits unrestricted use, distribution, and reproduction in any medium, provided the original author and source are credited. 
Rho activity was measured by affinity precipitation of GTPRho with Rhotekin-agarose beads (Rho activation assay kit,Upstate Biotechnology, Lake Placid, NY, USA) according to themanufacturer's instructions.

\section{Immunoblotting and immunoprecipitation}

Immunoblotting and immunoprecipitation were performed as described $(26,27)$. Briefly, cells were lysed in RIPA buffer. Equal amounts of protein for each sample were electrophoresed through a 10\% SDS-PAGE gel and blotted onto a hybond nitrocellulose membrane from Amersham (Piscataway, NJ). The membrane was blocked with 5\% nonfat milk solution and probed with appropriate antibodies. Proteins were detected with enhanced chemiluminiscence (ECL, Amersham Pharmacia Biotech).

Celllysateswere incubated with antibodiesforimmunoprecipitation. The immunocomplexes were separated on polyacrylamide gels by SDSPAGE. The Western blotting was performed as described above.

The Western blots were scanned and densities of bands were measured by Image-Pro Plus version 6.0 software. The relative density was calculated by dividing the percent value for each sample by the percent value of respective controls. Data represent mean \pm SD of three independent experiments.

\section{Invasion assay}

Matrigel invasion assays were performed as described [26] using transwell chambers ( $8 \mu \mathrm{M}$ pore size; Costar). Briefly, transwells were coated with growth factor reduced Matrigel. Subconfluent cell cultures were serum starved for $24 \mathrm{~h}$ and cell suspension was added to the upper chamber. NOV-002 $(10 \mu \mathrm{M}, 30 \mu \mathrm{M}, 100 \mu \mathrm{M}, 300 \mu \mathrm{M}, 1 \mathrm{mM})$ was added to the cell suspension. Complete medium was added to the bottom wells of the chambers. Cells migrated to the lower surface of the filters were fixed and stained. Images of three different X10 fields were captured from each membrane and the number of invading cells was counted. The mean of triplicate assays for each experimental condition was used.

\section{Orthotopic xenograft mouse model}

To establish the animal model for metastasis and NOV-002 treatment, $1 \mathrm{X} 10^{6} 4 \mathrm{~T} 1$-Luc cells were orthotopically transplanted into the mammary fat pads of 7 -week-old Balb/c mice. The treatment started on the second day of the cell transplantation. Mice were divided into four groups with 10 mice per group. In the control group, PBS (50 $\mu \mathrm{l}$ per mouse) were injected via intraperitoneal (IP) everyday for the first two weeks, and then five days a week for three weeks. In the NOV002 treatment group, NOV-002 (100 mg/day/kg) were injected via IP for the first two weeks, and then five days a week for three weeks. In the gemcitabine treatment group, gemcitabine ( $5 \mathrm{mg} / \mathrm{day} / \mathrm{kg}$ ) were injected via IP once a week for a total of five weeks. In the group of NOV-002 and gemcitabine combination treatment group, NOV-002 (100 mg/ day $/ \mathrm{kg}$ ) were injected via IP for the first two weeks, and then five days a week for three weeks; gemcitabine $(5 \mathrm{mg} / \mathrm{day} / \mathrm{kg})$ were injected via IP once a week for a total of five weeks. Mice bearing luciferase positive tumors were imaged post-transplantation using the bioluminescence Xenogen IVIS system as described [28].

\section{ErbB2 expression knockdown by short hairpin RNAs}

To generate retroviruses, human embryonic kidney (HEK) 293T cells were cotransfected with $1.0 \mu \mathrm{g}$ of a plasmid expressing Retro ErbB2 shRNA or nontarget shRNA and $0.5 \mu \mathrm{g}$ of SVA packaging plasmid using Lipifectamine 2000(Invitrogen) according to the manufacturer's specifications. Viruses were harvested after $48 \mathrm{~h}$ by filtering through $0.45 \mu \mathrm{m}$ filters (Millipore). Colo205 and A549 cells were transduced with the generated retroviruses and the knockdown efficiency was determined by immunobloting.

\section{Cell viability assay}

Cell viability was quantified using MTT Cell Growth Assay kit (Millipore) according to the manufactures protocol. Briefly, exponentially growing cells were seeded in triplicate in 96 -well flatbottomed tissue culture plates at $5 \times 10^{3}$ cells/well in $0.1 \mathrm{ml}$ medium and treated with $1 \mathrm{mM}$ final concentration of NOV-002. Control wells contained medium without drug. After $72 \mathrm{~h}$ treatment cells were incubated with $0.5 \mathrm{mg} / \mathrm{mL}$ MTT (3-(4,5-dimethylthiazol-2yl)-2,5-diphenyl tetrazolium bromide) for $4 \mathrm{~h}$ at $37^{\circ} \mathrm{C}$. At the end of the incubation, the purple MTT formazan crystals were dissolved by adding $0.1 \mathrm{~mL}$ isopropanol with $0.04 \mathrm{~N} \mathrm{HCl}$. Cell viability was then measured at $570 \mathrm{~nm}$ using a multi-well plate reader (Wallac Victor3, PerkinElmer). The ratio of cell viability was calculated with the equation as follows: (average absorbance of the $1 \mathrm{mM}$ compound)/ (average absorbance of the control) $\times 100$. Data represent mean \pm SD of three independent experiments.

\section{Statistical analysis}

Comparisons between the means of two data points were performed using the student $t$ test. A $p<0.05$ was considered statistically significant.

\section{Results}

We determined the effects of NOV-002 on cell invasion in cancer cell lines of various types. We found that NOV-002 suppresses cell invasion over in colon cancer cell HCT15, HCT116 and Colo205, breast cancer cell MDA-MB-436, lung cancer cell A549 and ovarian cancer cell SKOV3, in a dose-dependent manner (Figure 1 and Supplementary Figure 1). The percentage of suppression is over $90 \%$ with $1 \mathrm{mM} \mathrm{NOV}$ 002 treatment in all these cell lines (Figure 1). The effect on invasion by NOV-002 is not due to cytotoxicity as $1 \mathrm{mM}$ of NOV-002 does not affect cell death in these six cancer cell lines (Supplementary Figure 2). These results suggest that NOV-002 may affect molecules that are critical to invasion process.

It is suggested that the effects of NOV-002 on cell functions may be through its effects on cell surface proteins since oxidized glutathione

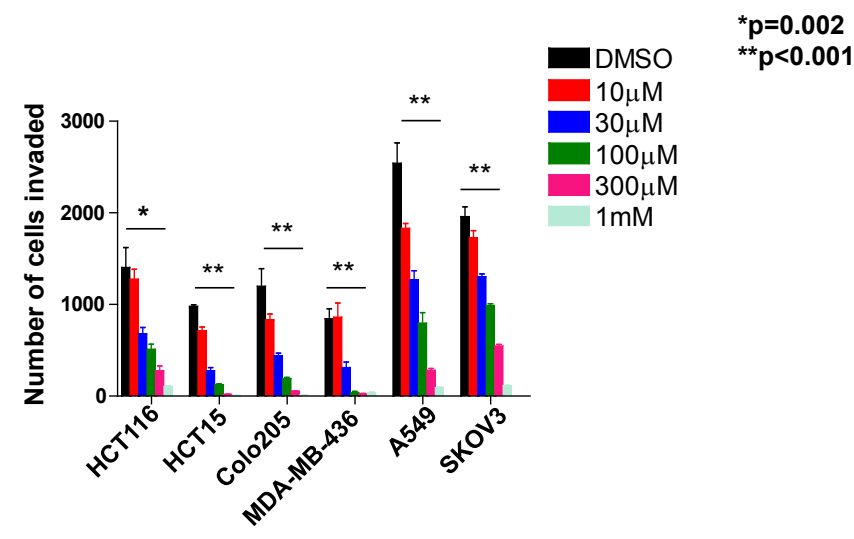

Figure 1: NOV-002 suppresses cell invasion. The graph represents the number of invaded cells from human tumor cell lines after the treatment of various doses of NOV-002 or control (water) in invasion assay. 
Citation: Gumireddy K, Li A, Cao L, Yan J, Liu L, et al. (2013) NOV-002, A Glutathione Disulfide Mimetic, Suppresses Tumor Cell Invasion and Metastasis. J Carcinogene Mutagene S7:002. doi:10.4172/2157-2518.S7-002

A

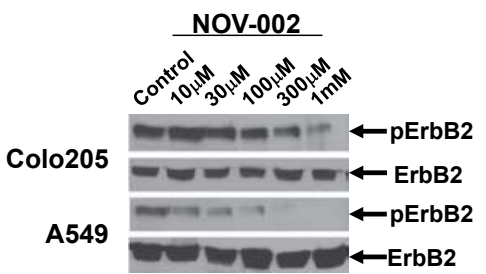

B



Figure 2: NOV-002 suppresses the phosphorylation of ErbB2 and PI3K subunit P85. (A) Immunoblots of phosphorylated ErbB2 and total ErbB2 in Colo205 and A549 cells with the treatment of various doses of NOV-002 or control (water). (B) Immunoblots of phosphorylated PI3K subunit P85 and total P85 in Colo205 and A549 cells with the treatment of various doses of NOV-002 or control (water). P85 phosphorylation was determined by immunoprecipitation using a P85 antibody, followed by immunoblot analysis with an antibody specific for phosphotyrosine.

(GSSG) does not passively cross cell membranes [29]. We determined the effects of NOV-002 on ErbB2 activation because ErbB2 has been shown to regulate cell invasion in cancer [17-21] and is regulated by redox mechanisms [26]. The level of ErbB2 phosphorylation was significantly reduced by $1 \mathrm{mMNOV-002} \mathrm{treatment} \mathrm{in} \mathrm{A549} \mathrm{and} \mathrm{Colo205}$ cells whereas total ErbB2 expression level was not affected, indicating NOV-002 suppresses ErbB2 activation (Figure 2A and Supplementary Figure 3). ErbB2 regulates multiple cell signaling pathways including PI3K pathway, MAPK pathway and SRC pathway $[10,12]$. We examined the effects of NOV-002 on PI3K activity which has been shown to play an important role in cell invasion and metastasis [3032]. It has been shown that the phosphorylation status of $P 85$ subunit of PI3K correlates with PI3K activity [33,34]. P85 phosphorylation was determined by immunoprecipitation using a P85 antibody, followed by immunoblot analysis with an antibody specific for phosphotyrosine. The level of P85 phosphorylation is dramatically reduced by the treatment of $1 \mathrm{mM}$ of NOV-002, indicating that NOV-002 suppresses PI3K activation (Figure 2B and Supplementary Figure 3). In order to determine whether ErbB2 is critical for cell invasion, we knocked down ErbB2 in A549 and Colo205 cells using short hairpin RNAs (shRNAs). Western blot analysis confirmed that ErbB2 expression is significantly reduced following the introduction of shRNAs (Supplementary Figure 4). Knockdown of ErbB2 resulted in the decrease of invasion in A549 and Colo205 cells (Supplementary Figure 5). These results indicated that knockdown of ErbB2 recapitulated the invasion suppression phenotype induced by NOV-002 treatment.

Serine-threonine kinase Akt and RhoA are two major signaling molecules downstream of PI3K activation that play critical role in cell invasion [35]. Akt is activated by phosphorylation at Thr308 and/or Ser473 site [36,37]. The active form of Akt is reduced by NOV-002 treatment (Figure 3A and Supplementary Figure 6) whereas total Akt expression levels are similar with or without NOV-002 treatment. Affinity precipitation of active RhoA from the cell extracts of A549 and
Colo205 revealed significant lower active RhoA expression after NOV002 treatment whereas total RhoA expression does not change with or without NOV-002 treatment (Figure 3B and Supplementary Figure 6). These results suggest that the activation of PI3K downstream signaling molecules Akt and RhoA are suppressed by NOV-002.

The activity of NOV-002 on metastasis was determined in a mouse xenograft model. It has been shown that mammary tumor cell line 4T1 causes lung metastasis when it is transplanted in mammary fat pads, representing an effective orthotopic xenograft model for metastasis $[27,38]$. ErbB2, PI3K, Akt and RhoA are expressed in 4T1 cells (data not shown), which also makes this cell line suitable for our study. Gemcitabine, a nucleoside analog, was chosen for combinatorial therapy with NOV-002 because it is used in the treatment of multiple cancer types such as non-small cell lung cancer, breast cancer, pancreatic cancer and bladder cancer. $4 \mathrm{~T} 1$ cells stably expressing a luciferase were used for the transplantation and luciferase signals detected by bioluminescence Xenogen system were used for the quantification of primary tumor and metastasis growth [27]. NOV002 alone does not affect primary tumor or metastasis growth (Figures $4 \mathrm{~A}, 4 \mathrm{~B}$ and $4 \mathrm{C}$ ) when compared with control treatment. Gemcitabine reduced primary tumor and metastasis growth by approximately $62 \%$ and $58 \%$ respectively five weeks after treatment when compared with control treatment (Figures $4 \mathrm{~B}$ and $4 \mathrm{C}$ ). NOV-002 in combination with gemcitabine suppressed primary tumor growth and metastasis by approximately $66 \%$ and $89 \%$ respectively when compared with control (Figures 4B and 4C). Although combinatorial treatment NOV-002 and gemcitabine showed no statistical difference on primary tumor growth when compared with gemcitabine treatment alone, the combination significantly suppressed metastatic tumor growth (Figures $4 \mathrm{~A}$ and $4 \mathrm{C}$ ). These results indicate that in combination with gemcitabine, NOV-002 suppresses metastasis in the mouse model.

\section{Discussion}

The results of our study indicated that NOV-002 suppresses ErbB2 phosphorylation, PI3K activation and their downstream targets AKT

A

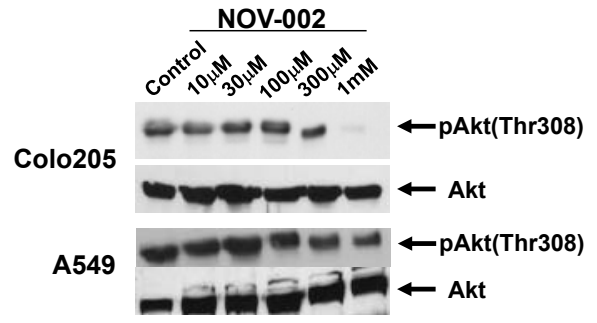

B

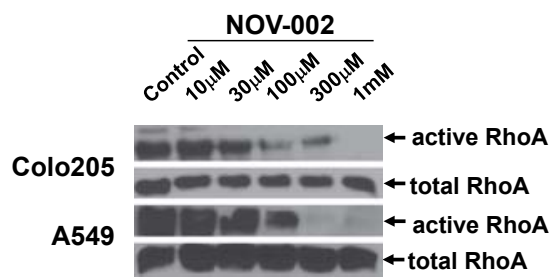

Figure 3: NOV-002 suppresses the activation of Akt and RhoA. (A) Immunoblots of phosphorylated Akt and total Akt in Colo205 and A549 cells with the treatment of various doses of NOV-002 or control (water). (B) Immunoblots of active RhoA and total RhoA in Colo205 and A549 cells with the treatment of various doses of NOV-002 or control (water). 
A

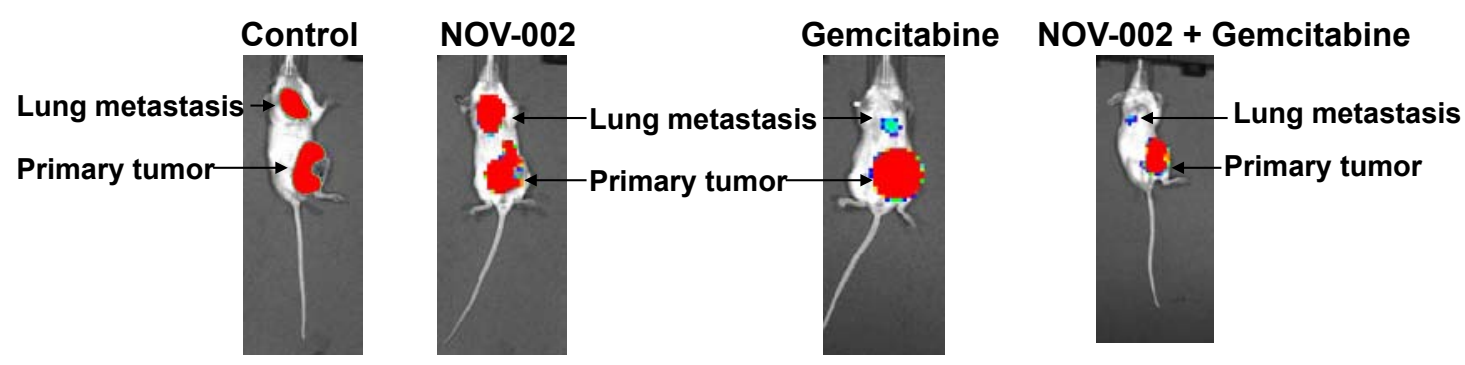

B

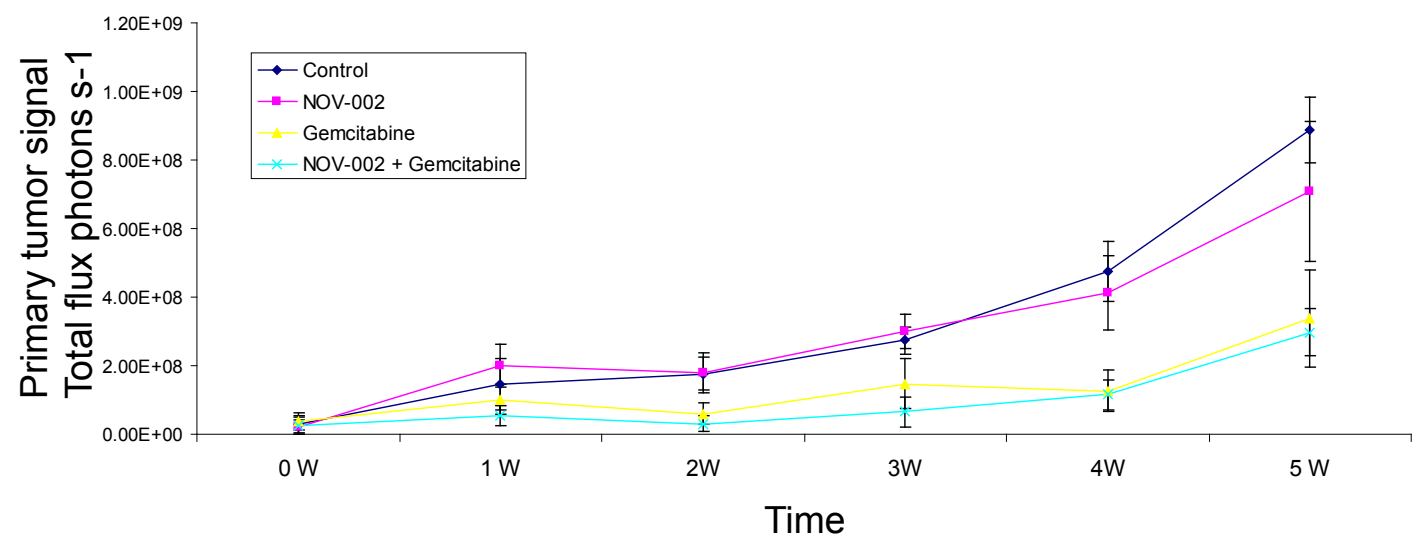

C

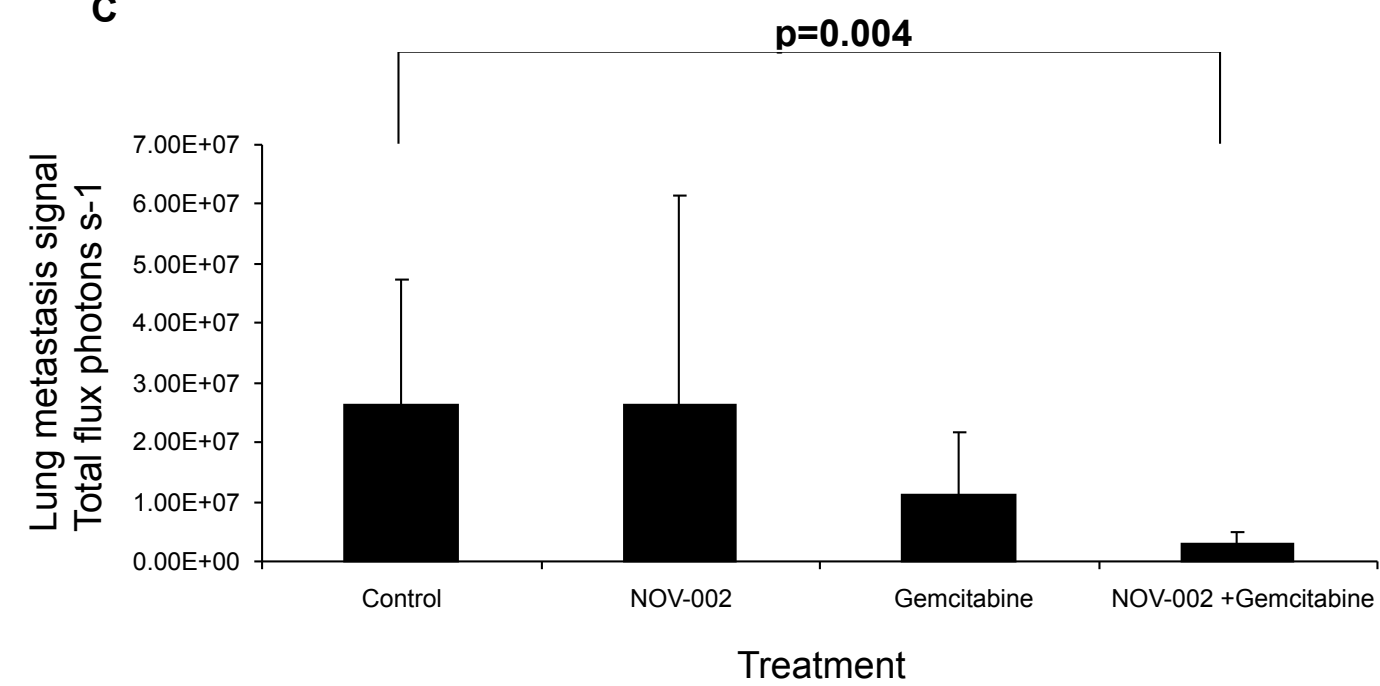

Figure 4: NOV-002 suppresses metastasis in combination with gemcitabine in a mouse model. (A) Bioluminescence imaging of lung metastasis and primary tumor. Images were taken five weeks following the treatment of control (PBS), NOV-002, gemcitabine or combination of NOV-002 and gemcitabine following the transplantation of breast cancer 4T1 cells in mammary fat pads. (B) Quantification of primary tumor growth with treatment of control (PBS), NOV-002, gemcitabine or combination of NOV-002 and gemcitabine following the transplantation of breast cancer 4T1 cells in mammary fat pads. (C) Quantification of metastasis growth after five weeks's treatment of control (PBS), NOV-002, gemcitabine or combination of NOV-002 and gemcitabine following the transplantation of breast cancer 4T1 cells in mammary fat pads. 12 .

and RhoA, which regulate cell invasion and metastasis (Supplementary Figure 7). Further studies are underway to investigate whether RhoA/ ROCK/LIMK/Cofilin signaling pathway downstream of RhoA and $\beta$-catenin activation downstream of AKT play important roles in the control of cell invasion and metastasis. It is possible that NOV-002 suppresses invasion and metastasis by regulating signaling molecules and pathways in addition to ErbB2 and PI3K. Further studies are needed to identify these molecules and pathways. 
Citation: Gumireddy K, Li A, Cao L, Yan J, Liu L, et al. (2013) NOV-002, A Glutathione Disulfide Mimetic, Suppresses Tumor Cell Invasion and Metastasis. J Carcinogene Mutagene S7:002. doi:10.4172/2157-2518.S7-002

Page 5 of 6

NOV-002 is a mimetic glutathione disulfide that can regulate redox homeostasis. Studies suggest that oxidized glutathione does not passively enter cell membrane [29]. Thus it is likely that the effect of NOV-002 on cell functions is mediated by the impact of GSSG on cell surface proteins. ErbB2 is a surface receptor that could potentially be one of the targets GSSG affects. Studies of whether ErbB2 is modified by glutathiolation and its impact on ErbB2 functions are currently underway. It is highly possible that GSSG affects additional cell surface proteins. It is imperative to develop systemic methods to identify these targets and study the mechanisms that GSSG alters the functions of its target proteins.

Although NOV-002 suppresses ErbB2 and PI3K activation in vitro, NOV-002 alone, which has no cytotoxicity even at high dosage, has no effect on primary tumor or metastasis growth in the mouse xenograft model. It is possible that tumor cells use alternative signaling pathways to compensate for the partial inactivation of ErbB2-PI3K pathway by NOV-002. Alternatively, ErbB2-PI3K pathway is not a major signaling pathway responsible for the metastatic phenotype of $4 \mathrm{~T} 1$ cells. It is possible that ErbB2-PI3K pathway becomes a dominant pathway for metastasis only after cells undergo stress such as gemcitabine treatment, which may explain the effectiveness of NOV-002 in metastasis suppression in combination with gemcitabine. Although clinical trial of NOV-002 in non-small cell lung cancer failed to show efficacy of survival improvement, it is possible that it can be effective in late stage cancer patients in combination with other chemotherapies.

Redox regulation is one of the critical aspects in cancer treatment. Cancer cells developed various mechanisms to cope with oxidized stress. It is possible that metastatic cells evolve to utilize different mechanisms than cells in the primary tumor to balance cellular redox. Therapies that change the balance of redox regulation in metastatic cancer cells may benefit metastasis treatment. Development of such therapies may aid the treatment of this deadly disease.

\section{Acknowledgements}

This study was partially funded by Novelos. QH is supported by NC R01CA148759-01, Breast Cancer Alliance, W. W. Smith, Edward Mallinckrodt J. Foundation. LC is supported by The National Natural Science Foundation of China (30873025) and the Natural Science Foundation of Shandong Province, P. R. China (No. ZR2010HM033)

\section{References}

1. Fidler IJ (2003) The pathogenesis of cancer metastasis: the 'seed and soil' hypothesis revisited. Nat Rev Cancer 3: 453-458.

2. Steeg PS (2006) Tumor metastasis: mechanistic insights and clinical challenges. Nat Med 12: 895-904.

3. Yan J, Huang Q (2012) Genomics screens for metastasis genes. Cancer Metastasis Rev 31: 419-428.

4. Chambers AF, Naumov GN, Vantyghem SA, Tuck AB (2000) Molecular biology of breast cancer metastasis. Clinical implications of experimental studies on metastatic inefficiency. Breast Cancer Res 2: 400-407.

5. Parker B, Sukumar S (2003) Distant metastasis in breast cancer: molecular mechanisms and therapeutic targets. Cancer Biol Ther 2: 14-21.

6. Gupta GP, Massagué J (2006) Cancer metastasis: building a framework. Cell 127: 679-695.

7. Gumireddy K, Huang Q (2010) Identification of metastasis genes by a functiona genomics approach. Cell Cycle 9: 423

8. Yan J, Yang Q, Huang Q (2013) Metastasis suppressor genes. Histol Histopathol 28: 285-292.

9. Citri A, Yarden Y (2006) EGF-ERBB signalling: towards the systems level. Nat Rev Mol Cell Biol 7: 505-516.
10. Yarden Y, Sliwkowski MX (2001) Untangling the ErbB signalling network. Nat Rev Mol Cell Biol 2: 127-137.

11. Hynes NE, Lane HA (2005) ERBB receptors and cancer: the complexity of targeted inhibitors. Nat Rev Cancer 5: 341-354.

12. Schlessinger $\mathrm{J}$ (2004) Common and distinct elements in cellular signaling via EGF and FGF receptors. Science 306: 1506-1507.

13. Slamon DJ, Clark GM, Wong SG, Levin WJ, Ullrich A, et al. (1987) Human breast cancer: correlation of relapse and survival with amplification of the HER2/neu oncogene. Science 235: 177-182.

14. Falck VG, Gullick WJ (1989) c-erbB-2 oncogene product staining in gastric adenocarcinoma. An immunohistochemical study. J Pathol 159: 107-111.

15. Tateishi M, Ishida T, Mitsudomi T, Kaneko S, Sugimachi K (1991) Prognostic value of c-erbB-2 protein expression in human lung adenocarcinoma and squamous cell carcinoma. Eur J Cancer 27: 1372-1375.

16. Stenman G, Sandros J, Nordkvist A, Mark J, Sahlin P (1991) Expression of the ERBB2 protein in benign and malignant salivary gland tumors. Genes Chromosomes Cancer 3: 128-135.

17. Yu D, Wang SS, Dulski KM, Tsai CM, Nicolson GL, et al. (1994) c-erbB-2/ neu overexpression enhances metastatic potential of human lung cancer cells by induction of metastasis-associated properties. Cancer Res 54: 3260-3266.

18. Li YM, Pan Y, Wei Y, Cheng X, Zhou BP, et al. (2004) Upregulation of CXCR4 is essential for HER2-mediated tumor metastasis. Cancer Cell 6: 459-469.

19. Tan M, Yao J, Yu D (1997) Overexpression of the c-erbB-2 gene enhanced intrinsic metastasis potential in human breast cancer cells without increasing their transformation abilities. Cancer Res 57: 1199-1205.

20. Guy CT, Webster MA, Schaller M, Parsons TJ, Cardiff RD, et al. (1992) Expression of the neu protooncogene in the mammary epithelium of transgenic mice induces metastatic disease. Proc Natl Acad Sci U S A 89: 10578-10582.

21. Muller WJ, Sinn E, Pattengale PK, Wallace R, Leder P (1988) Single-step induction of mammary adenocarcinoma in transgenic mice bearing the activated c-neu oncogene. Cell 54: 105-115.

22. Townsend DM, Pazoles CJ, Tew KD (2008) NOV-002, a mimetic of glutathione disulfide. Expert Opin Investig Drugs 17: 1075-1083.

23. Townsend DM, He L, Hutchens S, Garrett TE, Pazoles CJ, et al. (2008) NOV002 , a glutathione disulfide mimetic, as a modulator of cellular redox balance. Cancer Res 68: 2870-2877.

24. Tew KD (2007) Redox in redux: Emergent roles for glutathione S-transferase $P$ (GSTP) in regulation of cell signaling and S-glutathionylation. Biochem Pharmacol 73: 1257-1269.

25. Filomeni G, Rotilio G, Ciriolo MR (2003) Glutathione disulfide induces apoptosis in U937 cells by a redox-mediated p38 MAP kinase pathway. FASEB J 17: 64 66.

26. Gumireddy K, Sun F, Klein-Szanto AJ, Gibbins JM, Gimotty PA, et al. (2007) In vivo selection for metastasis promoting genes in the mouse. Proc Natl Acad Sci U S A 104: 6696-6701.

27. Gumireddy K, Li A, Gimotty PA, Klein-Szanto AJ, Showe LC, et al. (2009) KLF17 is a negative regulator of epithelial-mesenchymal transition and metastasis in breast cancer. Nat Cell Biol 11: 1297-1304.

28. Huang Q, Gumireddy K, Schrier M, le Sage C, Nagel R, et al. (2008) The microRNAs miR-373 and miR-520c promote tumour invasion and metastasis. Nat Cell Biol 10: 202-210.

29. Brennan JP, Miller JI, Fuller W, Wait R, Begum S, et al. (2006) The utility of $\mathrm{N}, \mathrm{N}$-biotinyl glutathione disulfide in the study of protein S-glutathiolation. Mol Cell Proteomics 5: 215-225.

30. Samuels Y, Ericson K (2006) Oncogenic PI3K and its role in cancer. Curr Opin Oncol 18: 77-82

31. Jiang BH, Liu LZ (2009) PI3K/PTEN signaling in angiogenesis and tumorigenesis. Adv Cancer Res 102: 19-65.

32. Hafsi S, Pezzino FM, Candido S, Ligresti G, Spandidos DA, et al. (2012) Gene alterations in the PI3K/PTEN/AKT pathway as a mechanism of drug-resistance (review). Int J Oncol 40: 639-644.

33. Fruman DA, Meyers RE, Cantley LC (1998) Phosphoinositide kinases. Annu Rev Biochem 67: 481-507. 
Citation: Gumireddy K, Li A, Cao L, Yan J, Liu L, et al. (2013) NOV-002, A Glutathione Disulfide Mimetic, Suppresses Tumor Cell Invasion and Metastasis. J Carcinogene Mutagene S7:002. doi:10.4172/2157-2518.S7-002

Page 6 of 6

34. Pleiman CM, Hertz WM, Cambier JC (1994) Activation of phosphatidylinositol-3 kinase by Src-family kinase SH3 binding to the p85 subunit. Science 263: 1609 1612.

35. Raftopoulou M, Hall A (2004) Cell migration: Rho GTPases lead the way. Dev Biol 265: 23-32.

36. Rane MJ, Coxon PY, Powell DW, Webster R, Klein JB, et al. (2001) p38 Kinase- dependent MAPKAPK-2 activation functions as 3-phosphoinositide-dependent kinase-2 for Akt in human neutrophils. J Biol Chem 276: 3517-3523.

37. Testa JR, Bellacosa A (2001) AKT plays a central role in tumorigenesis. Proc Natl Acad Sci U S A 98: 10983-10985.

38. Yang J, Mani SA, Donaher JL, Ramaswamy S, Itzykson RA, et al. (2004) Twist, a master regulator of morphogenesis, plays an essential role in tumor metastasis. Cell 117: 927-939.

This article was originally published in a special issue, Signal transduction-

Cancer handled by Editor(s). Dr. Li-Mei Chen, University of Central Florida

College of Medicine, United States 